\title{
Lead Time in Drug Procurement: A Study of Tertiary Care Teaching Hospital of North India
}

\author{
${ }^{1} \mathrm{H}$ Anand, ${ }^{2} \mathrm{~V}$ Siddharth, ${ }^{3} \mathrm{~V}$ Goyal, ${ }^{4} \mathrm{VK}$ Koushal
}

\begin{abstract}
Pharmaceutical procurement is a complex process that involves many steps, agencies, and manufacturers. Procurement lead time is defined as the time required to acquire the supplies and services and then placing them in the hands of the user. This study was done to study the lead time in drugs procurement at Government Medical College and Hospital, Chandigarh. It was aimed at calculating the average lead time in the procurement of drugs for year 2009-2010 in Pharmacy Department. Observational study along with retrospective record analysis was done to calculate the average internal and external lead time. Standardized format was used to retrieve data from the procurement records. Average lead time between the preparation of indent and receipt of drugs was observed to be 162 days, out of which 117 days (71\%) accounted for internal lead time and external lead time was 47 days (29\%). Internal lead time was approximately four times that of external lead time. Various reasons were noted for longer duration of internal lead time and every effort should be made to bring it down to the minimum, so as to ensure the availability of the right medicine in the right quantity, in the right time at the right place.
\end{abstract}

Keywords: Drug Procurement, Lead time, Pharmacy.

How to cite this article: Anand H, Siddharth V, Goyal V, Koushal VK. Lead Time in Drug Procurement: A Study of Tertiary Care Teaching Hospital of North India. Int J Res Foundation Hosp Healthc Adm 2016;4(1):16-19.

Source of support: Nil

Conflict of interest: None

\section{INTRODUCTION}

The goal of procurement is to deliver the best costeffective product to the ultimate user on a timely basis. ${ }^{1}$

\footnotetext{
${ }^{1}$ Consultant, ${ }^{2}$ Assistant Professor, ${ }^{3}$ Manager, ${ }^{4}$ Additional Professor

${ }^{1}$ Department of Maternal Health, National Health Mission Haryana, India

${ }^{2}$ Department of Hospital Administration, All India Institute of Medical Sciences, New Delhi, India

${ }^{3}$ Program Operations, Monitoring and Evaluation (Immunization), Public Health Foundation of India, India

${ }^{4}$ Department of Hospital Administration, Postgraduate Institute of Medical Education and Research, Chandigarh, India
}

Corresponding Author: V Siddharth, Assistant Professor Department of Hospital Administration, All India Institute of Medical Sciences, New Delhi, India, e-mail: dr.siddharthmamc@ gmail.com
An effective procurement process ensures the availability of the right medicines in the right quantities, at reasonable prices, at recognized standards of quality and, above all, at the right time. ${ }^{2}$ Pharmacy forms one of the essential and critical support services for any hospital; therefore, effective drug management becomes necessary. Pharmaceutical procurement is a complex process that involves many steps, agencies, and manufacturers. ${ }^{3}$

Delays in procurement can be unfortunate and the effects of nonavailability of the right drug at times can be disastrous in terms of morbidity and mortality. Proper drug management, therefore, can save money, which can be used for other health care needs, as it decreases maintenance, ordering, and other indirect costs associated with procurement.

Procurement lead time is defined as the average duration of time between the placing of the order and receipt of material. It may be divided into internal lead time (time required for organizational formalities to be completed for placing the order) and external lead time (time interval in placement of order and receipt of drugs). ${ }^{4}$ Lead time is one of the most important factors that drive procurement cycle and buffer stock, and tremendous gains can be realized by focusing on reducing lead times. Variability in lead time performance can lead to either excess or shortage of inventories, and sometimes both. ${ }^{5}$ Long procurement lead times result in capital being locked in the inventory to meet any unforeseen demand that could occur during the time, when supplies/items are being ordered, procured, and delivered. ${ }^{6}$ In materials management, this represents the one time plus the continued cost of holding and managing the inventory. The time, it takes to replenish the supplies directly determines the size of the inventory the health care organization must hold. ${ }^{1}$ A reduction in the inventory replenishment lead time allows reducing safety stock requirements and improving delivery of health care. ${ }^{5}$ It is easier to reduce internal lead time as factors affecting the same are under the control of the health care organization, and it can be reduced by $40 \%$ by streamlining the processes. External lead time cannot be avoided, but it may be minimized by timely reminders, judicious use, penalty for delayed supplies, etc. ${ }^{4}$

As there is little or no scientific literature on the lead times of procurement in Indian setting, this study was 
conducted to calculate lead time in drug procurement at a teaching tertiary care government hospital of north India.

\section{MATERIALS AND METHODS}

This study was descriptive, observational in nature and was carried out in the Pharmacy Department of Government Medical College and Hospital (GMCH), Chandigarh, for a period of 1 month (June 2010). All the drugs received during the financial year 2009-2010 were included in the study. A retrospective record analysis and unstructured interview of the assistant dispensing superintendent and other staff members were carried out to study the procurement process and identify various steps involved. A standardized format for data retrieval from the procurement files of various drugs was prepared, was validated by technical experts from Department of Hospital Administration and Pharmacy.

Thereafter, time spent at each step of procurement process was calculated, which was collated to arrive at average lead time, that is, both average internal and external lead times. The data were analyzed using Microsoft Excel software.

\section{RESULTS}

The GMCH, Chandigarh, is a 674-bedded multispecialty tertiary care hospital providing comprehensive health care, including preventive, curative, and rehabilitative health care. Pharmacy of the hospital has a modern set up and is responsible for the procurement of drugs and dressing material for the hospital. Pharmacy is divided into the following areas/section:

- OPD drug distribution center (OPD pharmacy)

- OPD counters for chest and TB as well as leprosy patients

- OPD injection room

- Drugs receipt section

- Drugs verification section and inspection area

- Bulk stores for:

- Dressing material

- I.V. fluids

- Main centralized drug stores

- Main centralized drug store for hospital issue and supplies

- Hospital issue counter

- Dispensing services area

- Emergency stocks/night dispensary area

- Record room

- Office of superintendent dispensary

- Office of Asstt. Superintendent Dispensary

- General office

In case of procurement of items between INR 1 and

10 lakhs, an agenda is prepared by the procurement branch under the guidance of the medical superintendent. The agenda is submitted for approval to the lower purchase committee and director principal, GMCH, who is the final approving authority. After approval, a purchase order is issued to the L1 (lowest quoting firm/company). For procurement exceeding rupees 10 lakh and up to rupees 25 lakh, approval by the standing purchasing committee is required.

The time period of various steps involved, between raising of demand and receipt of drugs, was documented. Both internal lead time and external lead time were calculated for all the drugs received in the year 2009-2010. The procurement process of total 123 drugs was studied.

\section{Internal Lead Time}

Various steps were identified by reviewing the office records and then the time consumed at each step was calculated to arrive at an internal lead time. The steps are detailed as follows:

- Time interval between demand preparation and verification.

- Time interval between demand verification and submission.

- Time interval between demand approval by medical superintendent and receipt of approved demand in pharmacy.

- Time interval between publishing of advertisement and opening of quotations.

- Time interval between quotation opening and comparative preparation.

- Time interval between comparative preparation and approval by lower purchase committee.

- Time interval between approval by lower purchase committee and issue of purchase order.

The following table provides the time taken at different steps contributing to internal lead time (Table 1).

Analysis of data on internal lead time revealed that in about $32 \%$ of drugs, the time interval between the preparation of demand and issue of purchase order was 40 to 80 days.

In $31 \%$ of drugs, the internal lead time was between 80 and 120 days. In about $20 \%$ of the drugs the internal lead time was 120 to 160 days. In 10\% of drugs, the internal

Table 1: Average time taken in various steps of internal lead time

\begin{tabular}{ll}
\hline Process & $\begin{array}{l}\text { Average } \\
\text { time (days) }\end{array}$ \\
\hline $\begin{array}{l}\text { Indent preparation and quotation opening } \\
\text { Quotation opening and comparative preparation }\end{array}$ & 70 \\
$\begin{array}{l}\text { Comparative preparation and issue of } \\
\text { purchase order }\end{array}$ & 41 \\
\hline $\begin{array}{l}\text { Total internal lead time (Demand preparation } \\
\text { and issue of purchase order) }\end{array}$ & 114 \\
\hline
\end{tabular}




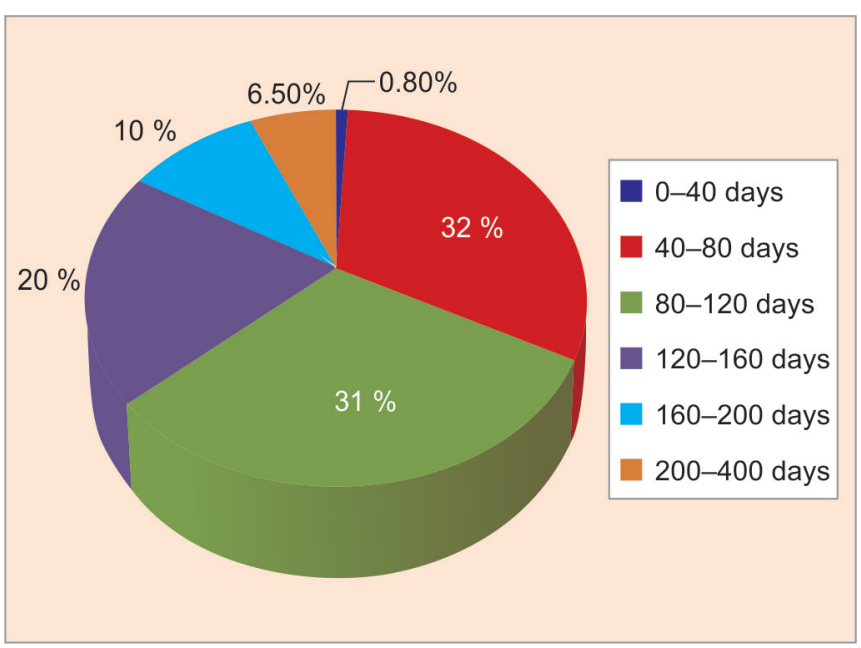

Graph. 1: Internal lead time (percentage of drugs)

Table 2: External lead time

\begin{tabular}{ll}
\hline No. of days & Percentage of drugs received \\
\hline $0-20$ & 16 \\
$20-40$ & 42 \\
$40-60$ & 27 \\
$60-360$ & 14.65 \\
\hline
\end{tabular}

lead time was 160 to 200 days and in the remaining (6.5\%) was between 200 and 400 days (Graph 1).

\section{External Lead Time}

In order to calculate the external lead time, the time interval between the issue of purchase order and the receipt of drugs in the hospital pharmacy was observed. The average external lead time was observed to be 47 days.

More than half $(58 \%)$ of the drugs were received within 20 to 40 days and $27 \%$ were received within 40 to 60 days. Only $5 \%$ of drugs took 60 to 80 days (Table 2).

\section{Total Lead Time}

Analysis of data revealed that $80 \%$ of the drugs were received within 200 days and $92 \%$ of the drugs were received within 250 days. Remaining $8 \%$ of the drugs were received within 550 days (Graph 2).

The following table gives the time consumed at various steps of drug procurement (Table 3).

Average lead time between the preparation of indent and receipt of drugs in the hospital pharmacy is 161 days (Table 4). The average internal lead time is 114 days and the average external lead time is 47 days. Only $59 \%$ of the drugs were received in time (Graph 3 ).

\section{CONCLUSION}

It was found that procurement of drugs is taking significant lead time in which internal lead time was identified to be four times that of external lead time. It is prudent to

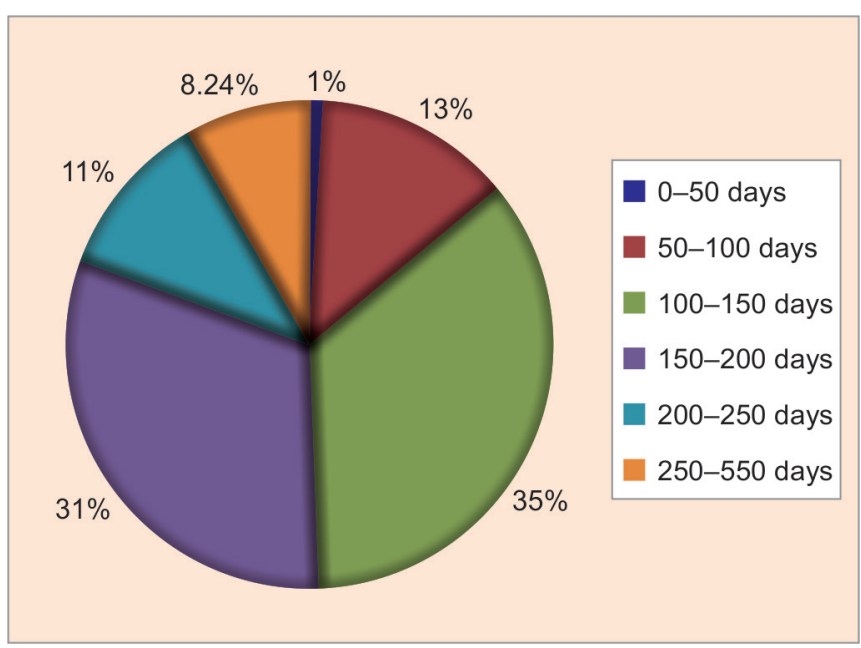

Graph 2: Time taken for receipt of various drugs received during the year 2009-2010

Table 3: Percentage of total time taken in various steps

\begin{tabular}{ll}
\hline Process & $\begin{array}{l}\text { Percentage } \\
\text { of time taken }\end{array}$ \\
\hline Indent preparation and quotation opening & 43.2 \\
Opening of quotation and making of comparative & 1.9 \\
Making of comparative and Issue of purchase order & 26 \\
Issue of purchase order and receipt of drug & 29 \\
\hline
\end{tabular}

Table 4: Lead time in drugs procurement

\begin{tabular}{|c|c|c|c|}
\hline $\begin{array}{l}\text { No. of } \\
\text { days }\end{array}$ & $\begin{array}{l}\text { Drugs } \\
\text { received }\end{array}$ & $\begin{array}{l}\text { Percentage of } \\
\text { drugs received }\end{array}$ & Cumulative \% \\
\hline $0-50$ & 1 & 0.81 & 0.81 \\
\hline $50-100$ & 16 & 13 & 13.81 \\
\hline $100-150$ & 42 & 35.20 & 49.01 \\
\hline 150-200 & 37 & 31 & 80.01 \\
\hline $200-250$ & 13 & 11 & 91.01 \\
\hline $250-300$ & 4 & 3.36 & 94.37 \\
\hline $300-350$ & 2 & 1.70 & 96.07 \\
\hline$>350$ & 4 & 3.20 & 99.27 \\
\hline
\end{tabular}

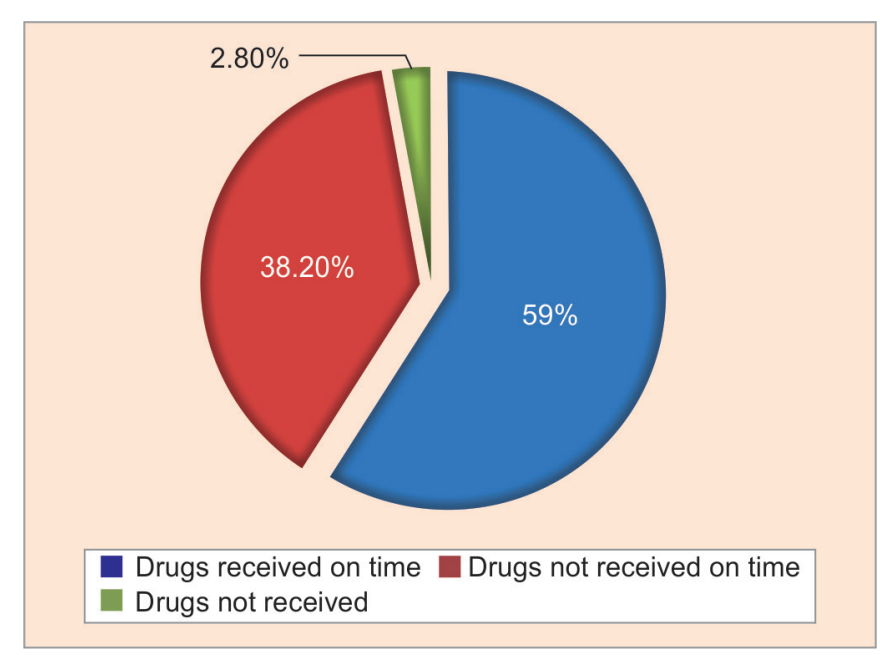

Graph 3: Timely receipt of drugs

streamline the various procurement processes to bring down the inventory cost and bring efficiency into the procurement system. As it is well known that the right 
quality of drug should be available in the right quantity at the right time at the right cost is the reflection of efficient and effective procurement system. Therefore, efforts should be made by the hospital to reduce it to as minimum as possible.

\section{REFERENCES}

1. Engelbeck RM. Acquisition management. Available from: http://books.google.co.in/books?id=ilAMFvx7rQkC\&prin tsec $=$ frontcover \&dq=R.+Marshall+Engelbeck+acquisition +management\&hl=en\&ei $=\mathrm{k}$ -

2. Good Pharmacy Practice - I.P.A. - C.D.S.C.O. - W.H.O. India Country Office (Module II). Available from: http://www.
whoindia.org/LinkFiles/GPP_Procurement_and_Inventory_ Management.pdf.

3. Operational Principles for Good Pharmaceutical Procurement. Essential Drugs and Medicines Policy Interagency Pharmaceutical Coordination Group Geneva; 1999. Available from: http://www.who.int/3by5/en/who-edm-par-99-5.pdf.

4. Gupta SK, Kant S. Hospital stores management - an integrated approach. New Delhi: Jaypee Publisher; 2007.

5. Chandra C, Grabis J. Inventory management with variable lead-time dependent procurement cost. Available from: http://cat.inist.fr/?aModele $=$ afficheN\&cpsidt $=20072514$.

6. The Impact of Lead Time Variability. Available from: http:// www.scdigest.com/assets/NewsViews/06-05-04-3.cfm? cid $=172 \&$ ctype $=$ content. 